\title{
Antibacterial activity of crude methanolic extract and fractions obtained from Larrea tridentata leaves
}

\author{
Silvia Martins ${ }^{a}$, Elba L.C. Amorim ${ }^{b}$, Tadeu J.S. Peixoto Sobrinho ${ }^{\text {b }}$, Antonio M. Saraiva ${ }^{c}$, \\ Maria N.C. Pisciottano ${ }^{c}$, Cristóbal N. Aguilar ${ }^{\mathrm{d}}$, José A. Teixeira ${ }^{\mathrm{a}}$, Solange I. Mussatto ${ }^{\mathrm{a}, *}$ \\ a Institute for Biotechnology and Bioengineering (IBB), Centre of Biological Engineering, University of Minho, Campus Gualtar, 4710-057 Braga, Portugal \\ ${ }^{\mathrm{b}}$ Laboratory of Natural Products, Department of Pharmaceutical Sciences, Federal University of Pernambuco, Avenida Prof. Moraes Rêgo, $50670-420$ Recife, Pernambuco, Brazil

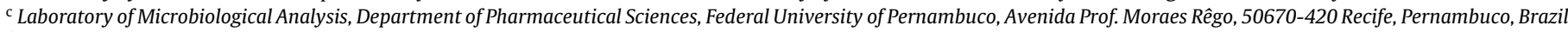 \\ d Food Research Department, School of Chemistry, Autonomous University of Coahuila, Blvd. Venustiano Carranza S/N Col. República Oriente, 25280, Saltillo, Coahuila, Mexico
}

\section{A R T I C L E I N F O}

\section{Article history:}

Received 24 January 2012

Received in revised form 17 April 2012

Accepted 18 April 2012

\section{Keywords:}

Larrea tridentata

Extraction

Antibacterial activity

Bioactive compounds

Minimal inhibitory concentration

\begin{abstract}
A B S T R A C T
The emergence of new infections and increase of bacteria drug-resistance rise up the urgent need for the development of new antibacterial agents from natural sources. This study was designed to evaluate the antibacterial activity of the crude methanolic extract $(\mathrm{CME})$ and fractions [hexane $(\mathrm{H})$, dichloromethane (DCM), ethyl acetate (EA) and ethanol (Et)] obtained from Larrea tridentata (Sessé \& Moc. Ex DC.) Coville leaves. The antibacterial activity was determined by the agar diffusion method against six strains of Gram-positive and Gram-negative bacteria. The micro-dilution method was applied for the determination of the minimal inhibitory concentration (MIC) of selected bacteria strains. HPLC analyses of tested samples were also carried out. The antibacterial activity of the samples was more effective inhibiting the growth of Gram-positive bacteria comparing with Gram-negative bacteria, mainly for the CME, DCM and EA fractions. EA fraction showed the highest antibacterial activity against methicillin-resistant Staphylococcus aureus isolated from secretion; with a MIC value $(31.3 \mu \mathrm{g} / \mathrm{mL})$ lower than the reference antibiotic tetracycline $(64 \mu \mathrm{g} / \mathrm{mL})$. Low MIC values $(62.5 \mu \mathrm{g} / \mathrm{mL})$ were also obtained for the CME and DCM fraction. CME and EA fraction presented the highest concentrations of quercetin, kaempferol and nordihydroguaiaretic acid. These compounds have important biological activities and could be responsible for at least part of the antibacterial activity of the CME, DCM and EA fractions. EA fraction from $L$. tridentata leaves was the most efficient to inhibit the growth of the bacterial strain methicillin-resistant S. aureus, which represents an important step for the search and development of a new antibacterial agent.
\end{abstract}

(C) 2012 Elsevier B.V. All rights reserved.

\section{Introduction}

Since human being existence, plants have been used for medicinal purposes and are the primary source of phytochemicals present in conventional medicaments. Ethnobotanical studies have described and explained the relationships between cultures and the traditional use of plants. These studies are of great importance and provide essential information that allows the development of scientific research more oriented to explore and prove the therapeutic potential of plants. Larrea tridentata (Sessé \& Moc. Ex DC.) Coville (Zygophyllaceae), commonly known as creosote bush, is a plant that grows in semiarid areas of Southwestern United States and Northern Mexico (Ross, 2005). This plant was traditionally

\footnotetext{
* Corresponding author. Tel.: +351 253604424; fax: +351 253604429

E-mail addresses: solange@deb.uminho.pt, solangemussatto@hotmail.com (S.I. Mussatto).
}

used for centuries by North American Indians to treat a wide range of medical conditions and illnesses including genitor-urinary and respiratory tract infections, inflammation of the musculoskeletal system, damage to the skin, kidney problems, arthritis, diabetes and cancer, among other diseases (Brinker, 1993; Ross, 2005). Over the past several years, the increase of bacteria drug-resistance and the rapid emergence of new infections have intensely decreased the efficiency of the drugs to treat pathologies caused by certain microorganisms. This situation rises up the urgent need for the development of new antibacterial agents, preferentially, from natural sources (Sánchez-Medina et al., 2001; Weckesser et al., 2007).

L. tridentata is an outstanding source of natural compounds with approximately $50 \%$ of the leaves (dry weight) being extractable matter (Arteaga et al., 2005). Among several valuable bioactive phenolic compounds found in this plant, the natural occurring lignan nordihydroguaiaretic acid (NDGA) has been pointed out as the most important, since it presents biological activities of large interest in the health area, such as antiviral, antimicrobial, and 
antitumorgenic (Hwu et al., 2008; Lambert et al., 2004). Other secondary metabolites identified in L. tridentata include lignans (dihydroguaiaretic acid, hemi-norisoguaiacin and norisoguaiacin), flavonoids (aglycones: apigenin and kaempferol; glycosides: chrysoeriol and quercetin), saponins (larreagenin A and larreic acid), triterpenes and triterpenoids (Brinker, 1993; Hui-Zheng et al., 1988; Jitsuno and Mimaki, 2010), among others. Some studies have demonstrated antimicrobial capacity of extracts from $L$. tridentata, such as antiviral (Brent, 1999), antifungal (Mojica-Marín et al., 2011; Tequida et al., 2002), and antibacterial activities (Verástegui et al., 1996). Nevertheless, to the best of our knowledge, no studies about the antibacterial activity of crude methanolic extract and specific fractions from $L$. tridentata leaves have been reported.

The purpose of this study was to evaluate the antibacterial activity of the crude methanolic extract and fractions (hexane, dichloromethane, ethyl acetate, and ethanol) from $L$. tridentata leaves against different bacteria species. High performance liquid chromatography analyses to identify and quantify some phytocomponents in the samples were also performed and are discussed.

\section{Materials and methods}

\subsection{Plant material and chemicals}

Plant material (L.tridentata) was collected from the Chihuahuan semidesert (North Coahuila, Mexico) during Spring season (April, 2010). Nordihydroguaiaretic acid (NDGA) was purchased from Sigma-Aldrich (Saint Louis, MO, USA). Reagent-grade methanol, hexane, dichloromethane, ethyl acetate and ethanol were from Vetec (Rio de Janeiro, Brazil). HPLC-grade acetonitrile was obtained from Fisher Scientific (Leicestershire, UK). Ultrapure water from a Milli-Q System (Millipore Inc., USA) was used.

\subsection{Extraction methodology and fractioning}

Air-dried leaves of $L$. tridentata were ground to fine powder and stored in dark bottles at room temperature for further analysis. Extraction was performed by mixing $1 \mathrm{~g}$ of plant material with $20 \mathrm{~mL}$ of $90 \%$ methanol and heating in a water-bath at $60-65^{\circ} \mathrm{C}$ for $20 \mathrm{~min}$. The obtained extract was filtered through qualitative filter paper and the solvent was removed by rotary evaporation under reduced pressure at temperatures below $45^{\circ} \mathrm{C}$. The resulting crude extract was then stored at $4{ }^{\circ} \mathrm{C}$ until further analysis. A portion of the crude methanolic extract $(10 \mathrm{~g})$ was fractioned by filter column chromatography over $100 \mathrm{~g}$ silica gel 60 (S) (Santos et al., 2009), and eluted with approximately $1 \mathrm{~L}$ of the solvents hexane, dichloromethane, ethyl acetate, and ethanol, in the order of increasing polarity, until a clear extract was obtained at the end of the elution. Pump pressure at approximately 5 bar was applied to accelerate the elution of the solvents. Eluates were collected in 1-L Erlenmeyer flasks and each fraction was subjected to evaporation under reduced pressure in a rotary evaporator. Fractions were stored at $4{ }^{\circ} \mathrm{C}$ until assayed.

\subsection{Antibacterial activity assays}

\subsubsection{Bacterial strains}

The organisms tested in these assays were obtained from the collection of the Laboratory of Microbiological Analysis (Federal University of Permambuco, Brazil). Antibacterial evaluations were performed against six Gram-positive bacteria strains: Staphylococcus aureus - standard strain ATCC 6538 (Sa1) and a methicillin-resistant $S$. aureus (MRSA) strain isolated from secretion (Sa2), Staphylococcus saprophyticus - standard strain LACEN (Ss), Staphylococcus epidermidis - isolated from catheter secretion (Se), Enterococcus faecalis - standard strain ATCC 51299 (Ef1) and a strain isolated from urine (Ef2); and six Gram-negative bacteria strains: Pseudomonas aeruginosa - standard strain ATCC 14502 (Pa1) and a strain isolated from blood (Pa2), Klebsiella pneumoniae - isolated from surgical wound secretion (Kp1) and from secretion (Kp2), Escherichia coli - standard strain ATCC 35218 (Ec1) and a strain isolated from secretion (Ec2).

\subsubsection{Antibacterial test using the agar diffusion method (well)}

A preliminary evaluation of the antibacterial activity of the crude methanolic extract and fractions from L. tridentata leaves was determined by the agar diffusion method using the well technique proposed by the Clinical and Laboratory Standards Institute (CLSI, 2009a). Briefly, all the samples were dissolved in dimethyl sulfoxide (DMSO $40 \%, v / v$ ) in order to obtain concentrations of $500,1000,2000$ and $4000 \mu \mathrm{g} / \mathrm{mL}$. Inoculum of the bacterial strains $\left(10^{8} \mathrm{CFU} / \mathrm{mL}\right)$ were then plated using sterile swabs into Petri dishes $(90 \mathrm{~mm})$ with $20 \mathrm{~mL}$ of Mueller-Hinton agar, where $6 \mathrm{~mm}$ wells were cut and filled with $100 \mu \mathrm{L}$ of sample $(50,100,200$ and $400 \mu \mathrm{g} /$ well $)$. Tetracycline $(100 \mu \mathrm{L}$ at a concentration of $300 \mu \mathrm{g} / \mathrm{mL}$, equivalent to $30 \mu \mathrm{g} /$ well) was used as positive control and DMSO $(40 \%, v / v)$ as negative control. The Petri dishes were pre-incubated for $3 \mathrm{~h}$ at room temperature, allowing the complete diffusion of the samples (Das et al., 2010; Möller, 1966) and, then, incubated at $37 \pm 1{ }^{\circ} \mathrm{C}$ for $24 \mathrm{~h}$. The agar diffusion method using the well technique is known for its advantage of allowing the use of adjuvants to improve the solubility of the extract constituents, as well as permitting its radial and superficial diffusion (Caetano et al., 2002). The complete diffusion of samples into the Mueller-Hinton agar was visually perceptible and confirmed. The antibacterial activity was determined by measuring of inhibition zone diameters $(\mathrm{mm})$ and was evaluated according the parameters suggested by Alves et al. (2000): inhibition zones <9 mm, inactive; 9-12 mm, less active; $13-18 \mathrm{~mm}$, active; $>18 \mathrm{~mm}$, very active.

\subsection{Determination of minimal inhibitory concentration (MIC)}

The evaluation of MICs was performed for the samples that showed an inhibition zone $\geq 13 \mathrm{~mm}$, using the micro-dilution methodology described by the Clinical and Laboratory Standards Institute (CLSI, 2009b). In these assays, other bacterial strains were also tested, including $S$. aureus MRSA strain isolated from tracheal secretion (Sa3), S. aureus MRSA strain isolated from secretion(Sa4), Staphylococcus coagulase-negative isolated from catheter secretion ( $\mathrm{Scn} 1)$, and S. coagulase-negative isolated from abdominal wound $(\mathrm{Scn} 2)$. The bacterial cell number was adjusted to approximately $10^{8} \mathrm{CFU}$ (colony forming unit)/mL ( 0.5 on the McFarland scale).

The crude methanolic extract and fractions $(100 \mathrm{mg} / \mathrm{mL})$ or pure compound (NDGA, $50 \mathrm{mg} / \mathrm{mL}$ ) were serially two-fold diluted to obtain the following concentrations $(\mu \mathrm{g} / \mathrm{mL})$ : $1000,500,250,125$, $62.5,31.3,15.6,7.8$, and 3.9. Each $20 \mu \mathrm{L}$ of bacterial suspensions was added to $90 \mu \mathrm{L}$ of physiologic serum and $80 \mu \mathrm{L}$ of Mueller-Hinton broth in a sterile 96 -well microplate. Afterwards, $10 \mu \mathrm{L}$ of the crude methanolic extract, DCM and EA fractions, and NDGA were added and the microplate was incubated at $37 \pm 1{ }^{\circ} \mathrm{C}$ for $24 \mathrm{~h}$. Then, $50 \mu \mathrm{L}$ of 2,3,5-triphenyltetrazolium chloride $(2.5 \mathrm{mg} / \mathrm{mL})$ were added and incubated again at $37 \pm 1{ }^{\circ} \mathrm{C}$ for $30 \mathrm{~min}$ in the dark (Klančnik et al., 2010). The growth or no-growth was assessed by the naked eye, and the MIC value was determined as being the lowest sample concentration that prevents viable bacteria to reduce the yellow dye into a pink color and exhibit complete inhibition of bacterial growth.

Several controls were considered: physiologic serum + Muller-Hinton broth+bacterial suspensions to verify microbial growth; physiologic serum + Muller-Hinton broth to control the sterility; aq. tetracycline or gentamicin solutions (at concentrations $0.125,0.25,0.5,1.0,2.0,4.0,8.0,16.0,32.0$ and $64 \mu \mathrm{g} / \mathrm{mL}$ ) as positive control; physiologic serum + Mueller-Hinton 
Table 1

Antibacterial activity of crude methanolic extract and fractions obtained from Larrea tridentata leaves.

\begin{tabular}{|c|c|c|c|c|c|c|c|c|c|c|c|c|c|}
\hline \multicolumn{2}{|c|}{ Tested samples ${ }^{\mathrm{a}}[\mu \mathrm{g} /$ well $]$} & \multicolumn{12}{|c|}{ Tested microorganisms ${ }^{\mathrm{b}}$} \\
\hline & & \multicolumn{6}{|c|}{ Gram-positive bacteria } & \multicolumn{6}{|c|}{ Gram-negative bacteria } \\
\hline & & Sa1 & $\mathrm{Sa} 2$ & Se & Ss & Ef1 & Ef2 & Pa1 & $\mathrm{Pa} 2$ & Ec1 & Ec2 & Кр1 & Kp2 \\
\hline & & \multicolumn{12}{|c|}{ Growth inhibition zone ${ }^{c}(\mathrm{~mm})$} \\
\hline \multirow[t]{5}{*}{ CME } & 400 & 22 & 21 & 21 & 20 & 16 & 16 & 13 & 11 & - & - & 11 & - \\
\hline & 200 & 19 & 18 & 18 & 17 & 13 & 14 & 11 & - & - & - & - & - \\
\hline & 100 & 16 & 15 & 16 & 14 & 11 & 12 & - & - & - & - & - & - \\
\hline & 50 & 13 & 13 & 14 & 12 & - & - & - & - & - & - & - & - \\
\hline & $\mathrm{TT}$ & 33 & 31 & 29 & 28 & - & - & 14 & - & 25 & 25 & 28 & 28 \\
\hline \multirow[t]{5}{*}{$\mathrm{H}$} & 400 & 10 & - & - & - & - & - & - & - & - & - & 11 & - \\
\hline & 200 & - & - & - & - & - & - & - & - & - & - & - & - \\
\hline & 100 & - & - & - & - & - & - & - & - & - & - & - & - \\
\hline & 50 & - & - & - & - & - & - & - & - & - & - & - & - \\
\hline & $\mathrm{TT}$ & 36 & 31 & 30 & 32 & 32 & 12 & 16 & 12 & 30 & 27 & 26 & 28 \\
\hline \multirow[t]{5}{*}{ DCM } & 400 & 22 & 21 & 20 & 20 & 16 & 17 & - & - & - & - & 9 & - \\
\hline & 200 & 20 & 18 & 17 & 17 & 14 & 15 & - & - & - & - & - & - \\
\hline & 100 & 17 & 16 & 14 & 15 & 12 & 13 & - & - & - & - & - & - \\
\hline & 50 & 15 & 14 & 12 & 13 & - & 11 & - & - & - & - & - & - \\
\hline & $\mathrm{TT}$ & 34 & 31 & 28 & 29 & - & - & 14 & - & 25 & 25 & 28 & 27 \\
\hline \multirow[t]{5}{*}{ EA } & 400 & 24 & 22 & 22 & 22 & 20 & 20 & 12 & 14 & 11 & - & 12 & - \\
\hline & 200 & 20 & 19 & 19 & 19 & 17 & 17 & - & 12 & - & - & 10 & - \\
\hline & 100 & 17 & 17 & 16 & 16 & 15 & 14 & - & - & - & - & - & - \\
\hline & 50 & 14 & 14 & 13 & 13 & 13 & 12 & - & - & - & - & - & - \\
\hline & TT & 32 & 29 & 34 & 31 & 34 & 12 & 18 & 12 & 27 & 26 & 27 & 28 \\
\hline \multirow[t]{5}{*}{ Et } & 400 & 11 & 12 & 9 & 10 & - & - & - & - & - & - & - & - \\
\hline & 200 & 9 & 9 & - & - & - & - & - & - & - & - & - & - \\
\hline & 100 & - & - & - & - & - & - & - & - & - & - & - & - \\
\hline & 50 & - & - & - & - & - & - & - & - & - & - & - & - \\
\hline & $\mathrm{TT}$ & 32 & 31 & 30 & 29 & - & - & 18 & - & 27 & 27 & 28 & 29 \\
\hline \multirow[t]{5}{*}{ NDGA } & 400 & 25 & 24 & 22 & 22 & 22 & 20 & 11 & 11 & 12 & 14 & 15 & 12 \\
\hline & 200 & 23 & 22 & 21 & 21 & 18 & 18 & - & - & 9 & 12 & 13 & 10 \\
\hline & 100 & 21 & 19 & 19 & 19 & 15 & 16 & - & - & - & - & 11 & - \\
\hline & 50 & 18 & 16 & 16 & 16 & 12 & 13 & - & - & - & - & - & - \\
\hline & $\mathrm{TT}$ & 32 & 31 & 28 & 28 & - & - & 15 & 10 & 26 & 25 & 27 & 28 \\
\hline DMSO & $20 \%$ & - & - & - & - & - & - & - & - & - & - & - & - \\
\hline
\end{tabular}

(-) no growth inhibition zone observed.

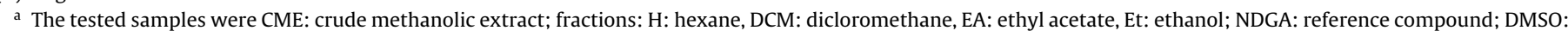
dimethyl sulfoxide, used as dilution solvent and negative control; TT: tetracycline, reference antibiotic used as positive control (30 $\mu \mathrm{g} /$ well).

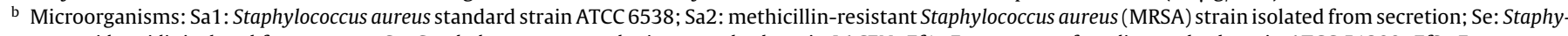

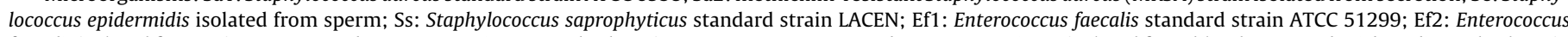

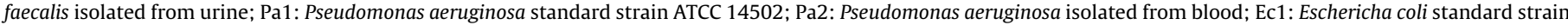

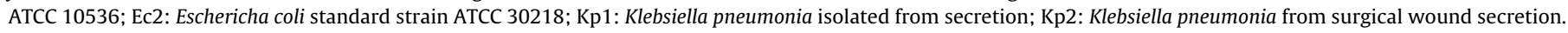

c Including the diameter of the hole $(6 \mathrm{~mm})$.

broth + bacterial suspensions + DMSO as negative control. All the assays were performed in triplicate for each sample against all bacterial strains. MIC values were determined as a mean value of each assay and evaluated as follows: $\leq 64 \mu \mathrm{g} / \mathrm{mL}$ was judged to show high activity, while $125-500$ and $1000 \mu \mathrm{g} / \mathrm{mL}$ were considered to show moderate and with no antibacterial activity, respectively (Yasunaka et al., 2005).

\subsection{Bioactive compounds quantification}

NDGA, kaempferol and quercetin concentrations were determined by high performance liquid chromatography (HPLC) on an equipment LC-10 A (Jasco, Japan) with a C18 $5 \mu \mathrm{m}$ $(3.9 \mathrm{~mm} \times 300 \mathrm{~mm})$ column at room temperature, and a UV detector at $280 \mathrm{~nm}$. The response of the detector was recorded and integrated using the Star Chromatography Workstation software (Varian). The mobile phase consisted of acetonitrile (solvent A) and $0.3 \%$ acetic acid in water $(\mathrm{v} / \mathrm{v})$ (solvent $B$ ) under the following gradient profile: $30 \% \mathrm{~A} / 70 \% \mathrm{~B}(0-2 \mathrm{~min}), 50 \% \mathrm{~A} / 50 \% \mathrm{~B}$ (2-11 min), $70 \% \mathrm{~A} / 30 \% \mathrm{~B}(11-17 \mathrm{~min}), 100 \% \mathrm{~A}(17-22 \mathrm{~min})$, and $30 \% \mathrm{~A} / 70 \%$ $\mathrm{B}(22-40 \mathrm{~min})$. The mobile phase was eluted in a flow rate of
$1.0 \mathrm{~mL} / \mathrm{min}$, and samples of $10 \mu \mathrm{L}$ were injected. Previous the analysis, all the extracts were filtered through $0.2 \mu \mathrm{m}$ membrane filters. NDGA, kaempferol and quercetin concentrations were expressed as the ratio between mass of the compound in the extracts and mass of plant material (dry weight).

\section{Results and discussion}

\subsection{Antibacterial activity by the agar diffusion method}

Agar diffusion techniques have been widely used to assay antimicrobial activity of plant extracts (Das et al., 2010; Perez et al., 1990; Rojas et al., 2006). In the present study, the use of this technique was useful to perform a screening study of the samples evaluating their antibacterial potential. The results of antibacterial activity obtained for the crude methanolic extract (CME) and fractions from L. tridentata leaves by the agar diffusion method are shown in Table 1. Overall, the antibacterial activity of the tested samples was noticeable more effective against the growth of Gram-positive bacteria strains compared to the Gram-negative bacteria strains. In fact, Gram-negative bacteria 
Table 2

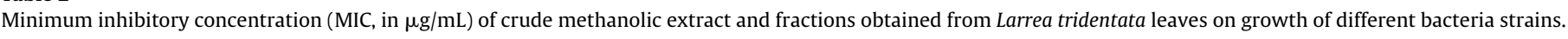

\begin{tabular}{|c|c|c|c|c|c|c|c|c|c|c|}
\hline \multirow[t]{2}{*}{ Tested samples ${ }^{\mathrm{a}}$} & \multicolumn{10}{|c|}{ Tested microorganisms ${ }^{\mathrm{b}}$} \\
\hline & Sa1 & $\mathrm{Sa} 2$ & Sa3 & $\mathrm{Sa} 4$ & Se & Ss & $\operatorname{Scn} 1$ & $\operatorname{Scn} 2$ & Ef1 & Ef2 \\
\hline CME & 125 & 125 & 62.5 & 62.5 & 125 & 125 & 250 & 62.5 & 187.5 & 250 \\
\hline DCM & 62.5 & 125 & 62.5 & 62.5 & 125 & 125 & 62.5 & 62.5 & 250 & 375 \\
\hline EA & 62.5 & 62.5 & 62.5 & 31.3 & 125 & 125 & 62.5 & 62.5 & 125 & 125 \\
\hline NDGA & 125 & 125 & 125 & 125 & 125 & 250 & 250 & 125 & 500 & 375 \\
\hline TT & 1.0 & 1.0 & 64 & 64 & 1.0 & 4.0 & 0.5 & 64 & - & - \\
\hline GEN & - & - & - & - & - & - & - & - & 64 & 64 \\
\hline
\end{tabular}

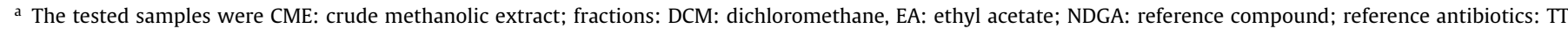
(tetracycline) and GEN (gentamicin).

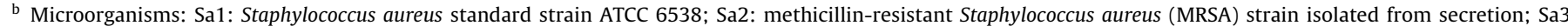

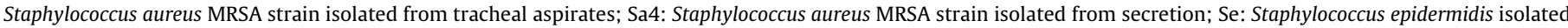

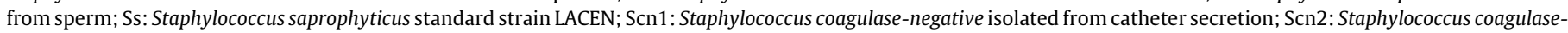
negative isolated from abdominal wound; Ef1: Enterococcus faecalis standard strain ATCC 51299; Ef2: Enterococcus faecalis isolated from urine.

are typically more resistant to antimicrobial agents than Grampositive bacteria, and this occurrence has been explained by the presence of an outer-membrane permeability barrier, which limits access of the antimicrobial agents to their targets in the bacterial cell (Vaara, 1992). In the present study, the highest concentration $(400 \mu \mathrm{g} /$ well) of the ethyl acetate (EA) extract was active inhibiting the growth of $\mathrm{Pa} 2$, and the highest concentration of NDGA was active against the growth of Ec2 and Kp1, the growth of the last one strain being also inhibited by a lower NDGA concentration, in the order of $200 \mu \mathrm{g} /$ well. No further relevant results were observed concerning the antimicrobial effect of the tested samples against Gram-negative bacteria strains. Verástegui et al. (1996) reported no inhibiting effect on the growth of Gram-negative Escherichia coli and Salmonella thyphimurium using an ethanolic extract (80\%) from L. tridentata leaves; nevertheless this extract inhibited the growth of Shigella dysenteriae and Yersinia enterocolitica strains with MIC values of $14 \pm 1$ and $10 \pm 1 \mathrm{mg} / \mathrm{mL}$, respectively.

Regarding to the antibacterial activity against Gram-positive bacteria, interesting results were found, in particular, for the CME, dichloromethane (DCM) and EA extracts, and the reference compound NDGA. All these samples were considered active or very active, depending on the concentration used, against Sa1, Sa2, Se and Ss bacteria strains, with exception of CME and DCM at concentration of $50 \mu \mathrm{g} /$ well for Ss and Se strains, respectively, presenting a less active effect. For the E. faecalis strains (Ef1 and Ef2) the most significant findings were observed using NDGA and EA fraction, which were very active inhibiting its growth at a concentration of $400 \mu \mathrm{g} /$ well. Some variability was observed in the activity of tetracycline against $E$. faecalis strains, which could be explained by some degree of heterogeneity of this antibiotic (Bismuth et al., 1990). No relevant results were obtained for the hexane $(\mathrm{H})$ and ethanol $(\mathrm{Et})$ fractions.

\subsection{Evaluation of minimal inhibitory concentration (MIC)}

Since the CME, DCM and EA fractions, and NDGA showed antibacterial activity against the tested Gram-positive bacteria strains, the real extend of their inhibitory activity was evaluated by determining MIC values, which are shown in Table 2 . As can be seen, the MIC values significantly varied to each sample, from 62.5 to $250 \mu \mathrm{g} / \mathrm{mL}$ for CME, from 62.5 to $375 \mu \mathrm{g} / \mathrm{mL}$ for DCM fraction, from 31.3 to $125 \mu \mathrm{g} / \mathrm{mL}$ for EA fraction, and from 125 to $500 \mu \mathrm{g} / \mathrm{mL}$ for the reference pure compound NDGA. The results obtained in these assays revealed that Sa4 (S. aureus - MRSA strain isolated from secretion) was the most sensitive bacteria to EA fraction, with a MIC value of $31.3 \mu \mathrm{g} / \mathrm{mL}$, which was lower than the reference antibiotic tetracycline $(64 \mu \mathrm{g} / \mathrm{mL})$. Low MIC values $(62.5 \mu \mathrm{g} / \mathrm{mL})$ for this strain were also obtained for CME and DCM fraction, compared to tetracycline. The strains Sa3 (S. aureus - MRSA strain isolated from tracheal aspirates) and $\operatorname{Scn} 2$ ( $S$. coagulase-negative isolated from abdominal wound) presented similar values of MIC $(62.5 \mu \mathrm{g} / \mathrm{mL})$ for the CME, DCM and EA fractions, which were also lower than that of the reference antibiotic $(64 \mu \mathrm{g} / \mathrm{mL})$. These results demonstrate that CME, DCM and EA fractions obtained from $L$. tridentata leaves present a high antibacterial activity. On the other hand, the MIC values obtained for the above mentioned bacteria strains using NDGA were higher than the values observed for CME, DCM and EA fractions, revealing that NDGA alone has a poor antibacterial activity. The efficiency of natural drugs might be explained by the synergistic or additive effects of several phytochemicals rather than arising from a single compound. Different bioactive compounds in a mixture can interact to provide a combined effect which is similar to the sum of the effects of the individual components (additive), or the combinations of bioactive compounds can exert effects that are greater than the sum of the individual components (synergistic) (Ginsburg and Deharo, 2011). The results previously described for the crude methanolic extract, fractions and the pure compound NDGA confirm the latter statement.

\subsection{HPLC analyses of tested samples}

In order to underlie the antibacterial activity of the crude methanolic extract and fractions from $L$. tridentata leaves, as well as to have a deepen knowledge about these samples, HPLC analyses were carried out and the chromatograms of CME, DCM and EA fractions are shown in Fig. 1. No relevant peaks were identified in HPLC chromatograms for $\mathrm{H}$ and Et fractions. Nevertheless, a previous phytochemical study performed by this research team showed the presence of several classes of chemical compounds in $\mathrm{H}$ and Et fractions, such as phenolic compounds, saponins, triterpenes and steroids, among others (data not shown). Despite the detection of different phytochemicals in these fractions, it is possible that these compounds have no antibacterial activity, which might explain the poor results observed with these fractions. On the other hand, several relevant peaks were observed for CME, DCM and EA fractions during HPLC analyses, among of which, three bioactive compounds were identified and quantified, namely, quercetin, kaempferol, and NDGA. These compounds are well known for their biological activities of great importance in the health area, such as antiviral, antimicrobial, antitumorgenic, anti-inflammatory, and antinociceptive capacities (De Melo et al., 2009; García-Mediavilla et al., 2007; Hwu et al., 2008; Lambert et al., 2004). These three bioactive compounds were found at different concentrations in the samples (Table 3), which could explain some of the differences on their antibacterial potential. The highest concentrations of quercetin, kaempferol and NDGA were observed in CME (8.67, 

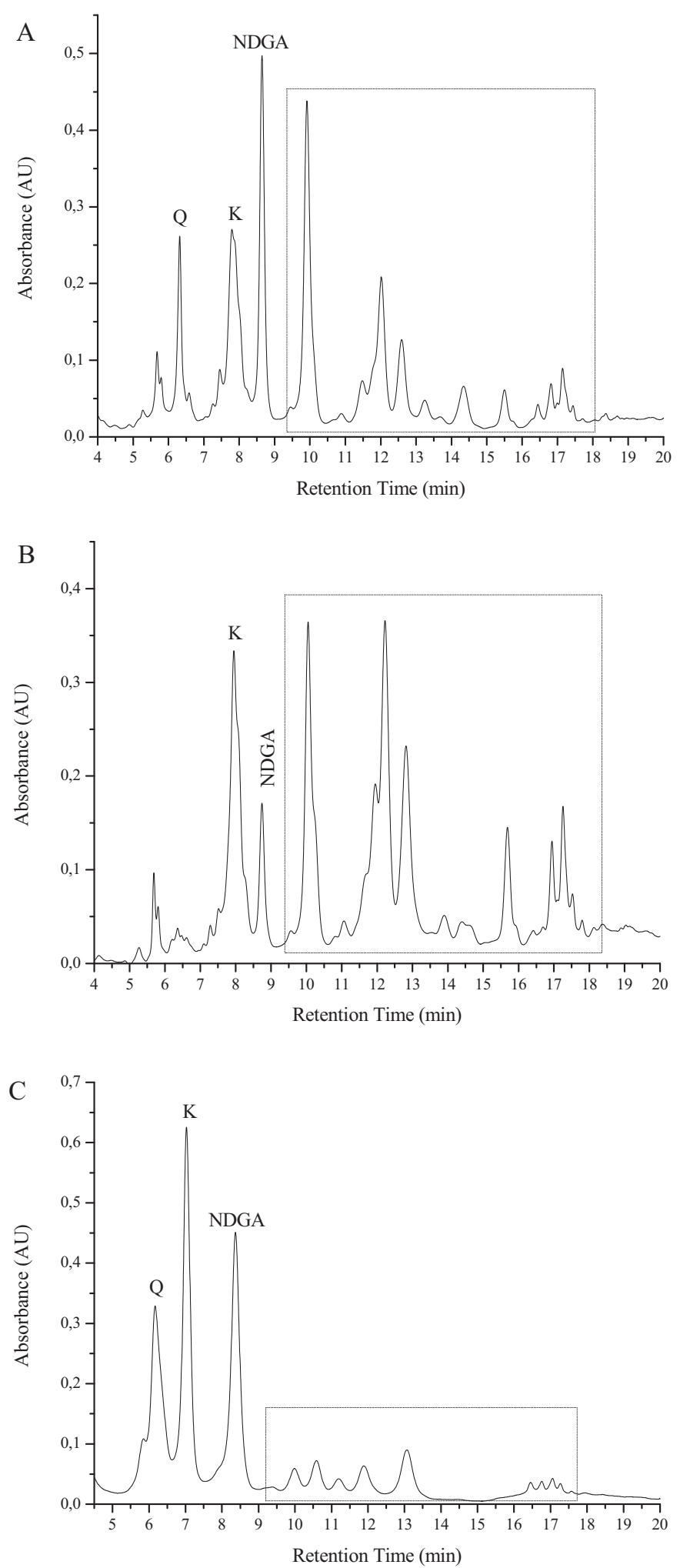

Fig. 1. HPLC chromatograms of crude methanolic extract, CME (A), dichloromethane, DCM (B) and ethyl acetate, EA (C) fractions from Larrea tridentata leaves (Q: quercetin; K: kaempferol; NDGA: nordihydroguaiaretic acid).

21.52 and $35.75 \mathrm{mg} / \mathrm{g}$ plant, respectively); nevertheless, EA fraction also showed considerable levels of these compounds compared with the remaining fractions, as it can be seen in Table 3 .

Another important aspect observed through HPLC analyses was a group of other non-identified phytochemicals (short dots area in
Table 3

Quantification of quercetin, NDGA and kaempferol (in $\mathrm{mg} / \mathrm{g}$ of plant material) in crude methanolic extract and fractions from Larrea tridentata leaves.

\begin{tabular}{llcc}
\hline Tested samples $^{\mathrm{a}}$ & Quercetin & Kaempferol & NDGA \\
\hline CME & 8.67 & 21.52 & 35.75 \\
H & - & - & - \\
DCM & 0.26 & 6.89 & 3.19 \\
EA & 8.45 & 11.89 & 16.51 \\
Et & 0.40 & 0.40 & 0.19 \\
\hline
\end{tabular}

a The tested samples were CME: crude methanolic extract; fractions: H: hexane DCM: dichloromethane, EA: ethyl acetate, Et: ethanol.

Fig. 1), which are clearly present at different concentration levels depending on the sample. These unidentified compounds could also be responsible for the biological characteristics, in particular the antibacterial activity, of the CME (Fig. 1A), and DCM and EA fractions (Fig. 1B and C, respectively). These observations indicate the need of additional research in order to identify all the phytocomponents comprised in each sample.

\section{Conclusions}

The findings of the present study demonstrated the potential of phytochemicals from $L$. tridentata leaves, a natural source, in the pathway of developing a novel antibacterial agent able of treating bacterial infections. Ethyl acetate fraction showed promising results against a methicillin-resistant $S$. aureus, which represents an important step for the search and development of a new antibacterial agent. Further toxicological and pharmacological studies will be useful to confirm the hypothesis of using phytochemicals from L. tridentata leaves.

\section{Acknowledgements}

The authors gratefully acknowledge FCT (Contract/grant numbers: SFRH/BD/40439/2007 and SFRH/BPD/38212/2007) for financial support of this work.

\section{References}

Alves, T.M.A., Silva, A.F., Brandão, M., Grandi, T.S.M., Smânia, E.F.A., Smânia Jr., A., Zani, C.L., 2000. Biological screening of Brazilian medicinal plants. Memórias do Instituto Oswaldo Cruz 95, 367-373.

Arteaga, S., Andrade-Cetto, A., Cárdenas, R., 2005. Larrea tridentata (Creosote bush), an abundant plant of Mexican and US-American deserts and its metabolite nordihydroguaiaretic acid. Journal of Ethnopharmacology 98, 231-239.

Bismuth, R., Zilhao, R., Sakamoto, H., Guesdon, J.-L., Courvalin, P., 1990. Gene heterogeneity for tetracycline resistance in Staphylococcus spp. Antimicrobial Agents and Chemotherapy 34, 1611-1614.

Brent, J., 1999. Three new herbal hepatotoxic syndromes. Journal of Toxicology: Clinical Toxicology 37, 715-719.

Brinker, F., 1993. Larrea tridentata (D.C.) Coville (Chaparral or Creosote Bush). British Journal of Phytotherapy 3, 10-30.

Caetano, N., Saraiva, A., Pereira, R., Carvalho, D., Pimentel, M.C.B., Maia, M.B.S., 2002 Determinação de atividade antimicrobiana de extratos de plantas de uso popular como antiinflamatório. Revista Brasileira De Farmacognosia 12, 132-135.

CLSI-Clinical and Laboratory Standards Institute, 2009a. Performance Standards for Antimicrobial Disk Susceptibility Tests, 10th ed. Approved Standard. Document M02-A10, CLSI, Wayne, PA.

CLSI-Clinical and Laboratory Standards Institute, 2009b. Methods for Dilution Antimicrobial Susceptibility Tests for Bacteria that Grow Aerobically, 17th ed. Approved Standard. Document M07-A8, CLSI, Wayne, PA.

Das, K., Tiwari, R.K.S., Shrivastava, D.K., 2010. Techniques for evaluation of medicinal plant products as antimicrobial agent: current methods and future trends. Journal of Medicinal Plants Research 4, 104-111.

De Melo, G.O., Malvar, D.C., Vanderlinde, F.A., Rocha, F.F., Pires, P.A., Costa, E.A. Matos, L.G., Kaiser, C.R., Costa, S.S., 2009. Antinociceptive and anti-inflammatory kaempferol glycosides from Sedum dendroideum. Journal of Ethnopharmacology $124,228-232$.

García-Mediavilla, V., Crespo, I., Collado, S., Esteller, A., Sánchez-Campos, S., Tuñón, M.J., González-Gallego, J., 2007. The anti-inflammatory flavones quercetin and kaempferol cause inhibition of inducible nitric oxide synthase, cyclooxygenase2 and reactive $C$-protein, and down-regulation of the nuclear factor kappaB pathway in Chang. Liver Cells 557, 221-229. 
Ginsburg, H., Deharo, E., 2011. A call for using natural compounds in the development of new antimalarial treatments-an introduction. Malaria Journal 10, S1.

Hui-Zheng, X., Zhi-Zhen, L., Chohachi, K., Soejarto, D.D., Cordell, G.A., Fong, H.H.S., Hodgson, W., 1988. 3 $\beta$-(3,4-Dihydroxycinnamoyl)-erythrodiol and $3 \beta-$ (4-hydroxycinnamoyl)-erythrodiol from Larrea tridentata. Phytochemistry 27, 233-235.

Hwu, J.R., Hsu, M.H., Huang, R.C., 2008. New nordihydroguaiaretic acid derivates as anti-HIV agents. Bioorganic \& Medicinal Chemistry Letters 18, 1884-1888.

Jitsuno, M., Mimaki, Y., 2010. Triterpene glycosides from the aerial parts of Larrea tridentata. Phytochemistry 71, 2157-2167.

Klančnik, A., Piskernik, S., Jeršek, B., Možina, S.S., 2010. Evaluation of diffusion and dilution methods to determine the antibacterial activity of plant extracts. Journal of Microbiological Methods 81, 121-126.

Lambert, J.D., Dorr, R.T., Timmermann, N., 2004. Nordihydroguaiaretic acid: a review of its numerous and varied biological activities. Pharmaceutical Biology 42, 149-158.

Mojica-Marín, V., Luna-Olivera, H.A., Sandoval-Coronado, C.F., Morales-Ramos, L.H., González-Aguilar, N.A., Pereyra-Alférez, B., Ruiz-Baca, E., Elías-Santos, M., 2011. In vitro antifungal activity of Gobernadora (Larrea tridentata (D.C.) Coville) against Phytophthora capsici Leo. African Journal of Agricultural Research 6, 1058-1066.

Möller, A.J.R., 1966. Microbiological examination of root canals and periapical tissues of human teeth. Odontolgisk Tidskrift 74, 1-38.

Perez, C., Pauli, M., Bazevque, P., 1990. An antibiotic assay by the agar well diffusion method. Acta Biologia Y Medicina Experimentales 15, 113-115.

Rojas, J.J., Ochoa, V.J., Ocampo, S.A., Muñoz, J.F., 2006. Screening for antimicrobial activity of ten medicinal plants used in Colombian folkloric medicine: a possible alternative in the treatment of non-nosocomial infections. BMC Complementary and Alternative Medicine 6, 2.
Ross, I.A., 2005. Medicinal Plants of the World-Chemical Constituents, Traditional and Modern Medicinal Uses, vol. 3. Humana Press, New Jersey.

Santos, A.K.L., Magalhães, T.S., Monte, F.J.Q., Mattos, M.C., Oliveira, M.C.F. Almeida, M.M.B., Lemos, T.L.G., Braz-Filho, R., 2009. Alcalóides iboga de Peschiera affinis (Apocynaceae)-atribuição inequívoca dos deslocamentos químicos dos átomos de hidrogênio e carbono. Quimica Nova 32, 1834-1838.

Sánchez-Medina, A., García-Sosa, K., May-Pat, F., Peña-Rodríguez1, L.M., 2001. Evaluation of biological activity of crude extracts from plants used in Yucatecan Traditional Medicine Part I. Antioxidant, antimicrobial and $\beta$-glucosidase inhibition activities. Phytomedicine 8, 144-151.

Tequida, M., Cortez, R., Rosas, B., Lopez, S., Corrales, M., 2002. Effect of alcoholic extracts of wild plants on the inhibition of growth of Aspergillus flavus, Aspergillus niger, Penicillium chrysogenum, Penicillium expansum, Fusarium moniliforme and Fusarium poae moulds. Revista Iberoamericana de Micologia 19, 84-88 (in Spanish).

Vaara, M., 1992. Agents that increase the permeability of the outer membrane. Microbiological Reviews 56, 395-411.

Verástegui, M.A., Sánchez, C.A., Heredia, N.L., García-Alvarado, J.S., 1996. Antimicrobial activity of extracts of three major plants from the Chihuahuan desert. Journal of Ethnopharmacology 52, 175-177.

Yasunaka, K., Abe, F., Nagayama, A., Okabe, H., Lozada-Pérez, L., López-Villafranco, E., Muñiz, E.E., Aguilar, A., Reyes-Chilpa, R., 2005. Antibacterial activity of crude extracts from Mexican medicinal plants and purified coumarins and xanthones. Journal of Ethnopharmacology 97, 293-299.

Weckesser, S., Engel, K., Simon-Haarhaus, B., Wittmer, A., Pelz, K., Schempp, C.M., 2007. Screening of plant extracts for antimicrobial activity against bacteria and yeasts with dermatological relevance. Phytomedicine 14, 508-516. 